\title{
Postulated Physiological Roles of the Seven-carbon Sugars, Mannoheptulose, and Perseitol in Avocado
}

\author{
Xuan Liu, ${ }^{1}$ James Sievert, Mary Lu Arpaia, and Monica A. Madore ${ }^{2}$ \\ Department of Botany and Plant Sciences, University of California, Riverside, CA 92521
}

\begin{abstract}
AdDitional INDEX wORDs. 'Hass' avocado on 'Duke 7' rootstock, phloem transport, ripening, Lauraceae
Abstract. Avocado (Persea americana Mill.) tissues contain high levels of the seven-carbon (C7) ketosugar mannoheptulose and its polyol form, perseitol. Radiolabeling of intact leaves of 'Hass' avocado on 'Duke 7' rootstock indicated that both perseitol and mannoheptulose are not only primary products of photosynthetic $\mathrm{CO}_{2}$ fixation but are also exported in the phloem. In cell-free extracts from mature source leaves, formation of the $\mathrm{C} 7$ backbone occurred by condensation of a three-carbon metabolite (dihydroxyacetone-P) with a four-carbon metabolite (erythrose-4-P) to form sedoheptulose-1,7bis-P, followed by isomerization to a phosphorylated D-mannoheptulose derivative. A transketolase reaction was also observed which converted five-carbon metabolites (ribose-5-P and xylulose-5-P) to form the C7 metabolite, sedoheptulose-7-P, but this compound was not metabolized further to mannoheptulose. This suggests that $\mathrm{C} 7$ sugars are formed from the Calvin Cycle, not oxidative pentose phosphate pathway, reactions in avocado leaves. In avocado fruit, $\mathrm{C} 7 \mathrm{sugars}$ were present in substantial quantities and the normal ripening processes (fruit softening, ethylene production, and climacteric respiration rise), which occurs several days after the fruit is picked, did not occur until levels of $\mathrm{C} 7 \mathrm{sugars}$ dropped below an apparent threshold concentration of $\approx 20 \mathrm{mg} \cdot \mathrm{g}^{-1}$ fresh weight. The effect of picking could be mimicked by girdling the fruit stalks, which resulted in ripening on the tree. Again, ripening followed a decline in $\mathrm{C} 7 \mathrm{sugars}$ to below an apparent threshold level. Taken together, these data indicate that the $\mathrm{C} 7$ sugars play important roles in carbon allocation processes in the avocado tree, including a possible novel role as phloem-mobile ripening inhibitors.
\end{abstract}

Avocado (Persea americana, Lauraceae), a subtropical evergreen tree fruit, is recognized as one of the top 20 commercial fruit crops (excluding melons and nuts) produced in the world (Whiley and Schaffer, 1994). From a biochemical and physiological standpoint, the avocado tree is interesting as the seven-carbon (C7) sugar mannoheptulose and a related C7 sugar alcohol, perseitol (Fig. 1), represent major forms of nonstructural carbohydrates in the tree (Liu et al., 1999a). The C7 sugars often account for over $10 \%$ of the tissue dry weight, and can be found in substantial amounts in all tissues and organs, even the peel and seed of the fruit (Liu et al., 1999a, 1999b). In comparison, the more commonly occurring nonstructural carbohydrates based on a six-carbon hexose skeleton, such as glucose, sucrose, and even starch, are found in much lower amounts in avocado tissues.

Despite their obvious importance in avocado, little is known about the biochemical synthesis or metabolism of the $\mathrm{C} 7$ sugars. The biochemical pathway which produces the seven-carbon chain is not known, although there are at least three known enzymatic reactions that will generate a $\mathrm{C} 7$ intermediate: a) an aldolase reaction: erythrose-4-P + dihydroxyacetone-P $\leftrightarrow$ sedoheptulose-1,7-bis-P; b) a transketolase reaction: xylulose-5-P + ribose-5-P $\leftrightarrow$ sedoheptulose-7-P + glyceraldehyde-3-P; or c) a transaldolase reaction: fructose- $6-\mathrm{P}+$ erythrose $-4-\mathrm{P} \leftrightarrow$ sedoheptulose-7-P + glyceraldehyde-3-P.

Note that the first reaction generates a bis-phosphorylated C7 sugar, while the latter two generate a monophosphorylated intermediate. The first reaction is common to all photosynthetic tissues, as it is key Calvin Cycle reaction (Bowyer and Leegood, 1997). Reactions $b$ and $c$ are more typical of the oxidative pentose

Received for publication 1 Feb. 2001. Accepted for publication 12 Sept. 2001. This project was funded, in part, by a grant-in-aid from the California Avocado Commission. The cost of publishing this paper was defrayed in part by the payment of page charges. Under postal regulations, this paper therefore must be hereby marked advertisement solely to indicate this fact.

${ }^{1}$ Present address: George E. Brown, Jr., Salinity Laboratory, 450 West Big Springs Rd., Riverside, CA 92507.

${ }^{2}$ Corresponding author; e-mail: madore@ mail.ucr.edu. phosphate pathway (Brownleader et al., 1997) (although the transketolase reaction also occurs during the Calvin cycle but operates in the reverse direction to that shown above). All of the above reactions are fully reversible, and so in theory could be responsible for either synthesis or degradation of a C7 sugar phosphate. Although it has been reported that avocado leaves readily synthesize the $\mathrm{C} 7$ sugar mannoheptulose during periods of photosynthesis (Bean et al., 1963), it is still not clear which Calvin cycle intermediates are the starting products for the assembly of the mannoheptulose $\mathrm{C} 7$ backbone or where in the leaf cell this assembly takes place.

Mannoheptulose, the first naturally occurring ketoheptose identified (LaForge, 1916), has been reported in a wide variety of plants, including alfalfa (Medicago sativa L.) (Rendig and McComb, 1964), avocado (LaForge, 1916; Nordal and Benson, 1954; Richtmyer, 1970), fig (Ficus officinalis L.) (Bevenue et al., 1961), and primrose (Primula officinalis Jacq.) (Begbie and Richtmyer, 1966). In fact, mannoheptulose may prove to be<smiles>O=C(CO)[C@@H](O)[C@H](O)[C@H](O)[C@H](O)CO</smiles>

Sedoheptulose<smiles>O=C(CO)[C@H](O)[C@H](O)[C@H](O)[C@H](O)CO</smiles>

Mannoheptulose<smiles>OC[C@@H](O)[C@H](O)[C@H](O)[C@H](O)[C@H](O)CO</smiles>

Perseitol
Fig. 1. Chemical structures of three seven-carbon (C7) sugars occurring in avocado. 
ubiquitous in the plant kingdom, as improved detection and separation methods have since allowed its identification in a wide number of species, including 3 classes of gymnosperms, 21 dicot families, and 2 monocots (Okuda and Mori, 1974). However, for reasons that are still unclear, it is only in avocado that extremely high levels of this sugar are found.

The unusually high levels of mannoheptulose and its polyol equivalent, perseitol (Liu et al., 1999a), in avocado may represent an amplification of the biosynthetic pathway for C7 sugars, but at the present time we have no clear idea what the steps in this biosynthetic pathway may be. Similarly, the reductive pathway leading to the production of the $\mathrm{C} 7$ polyol, perseitol, has not been characterized. Further unanswered questions include the nature of the control mechanisms which allow carbon to be partitioned preferentially to $\mathrm{C} 7$ sugar pathways and away from the more conventional hexose-based carbohydrate pathways leading to sucrose or starch. How C7 sugars are allocated to the many different plant tissues in which they are found is also unknown. Therefore, the goal of this research was to further characterize carbon partitioning and allocation processes in the avocado tree, focusing on the usage and role of the predominant C7 sugars, mannoheptulose and perseitol, in these processes.

\section{Materials and Methods}

Plant Material. Mature ( $\approx 7$-year-old) 'Hass' avocado trees on clonal 'Duke 7' rootstock grown either at an avocado research plot on the campus of the University of California, Riverside, or at the University of California South Coast Research and Extension Center, Irvine, were used for all experiments. Trees were dripirrigated as needed using reference evapotranspiration guidelines from the California Irrigation Management Information System (CIMIS) (Snyder et al., 1985). Standard fertilization practices were maintained (Goodall et al., 1981) and leaf mineral nutrient analyses were performed annually and fertilization adjusted so that leaf nutrient levels remained within the recommended guidelines(Goodall et al., 1981).

Chemicals. D-mannoheptulose and perseitol were purchased from Pfanstiehl Laboratories (Waukegon, Ill.). All other chemicals were obtained from Sigma-Aldrich Biochemicals (St. Louis). Sedoheptulose was obtained by dissolving sedoheptulosan in $1 \% \mathrm{HCl}$ and heating it in boiling water for $30 \mathrm{~min}$ (LaForge and Hudson, 1917).

Carbohydrate content of avocado tissues. Tissue samples (1 to $5 \mathrm{~g}$ ) from mature leaves, immature leaves, trunk cambium, stems, roots, flower parts (pistils and stamens), mature fruit (flesh, peel, and seed) were collected at midday during 2 weeks in April 1996 from trees growing in a field plot in Irvine, Calif. Nectar samples $(\approx 10$ $\mathrm{mL}$ ) were also collected by holding a capillary tube against exuding floral nectaries. All samples were transferred to the laboratory in thermal ice chests for further processing essentially as described previously (Liu et al., 1999a, 1999b). Tissue samples were freezedried for $48 \mathrm{~h}$ at $-50{ }^{\circ} \mathrm{C}$ (Freezone 4.5 freeze-dryer; Labconco, Kansas City, Mo.) then the freeze-dried tissues were ground using a Wiley mill to pass a $40-$ mesh $(0.635-\mathrm{mm})$ screen. Samples $(0.05$ to $0.10 \mathrm{~g}$ each) were then weighed and extracted in $4 \mathrm{~mL} 80 \%(\mathrm{v} / \mathrm{v})$ ethanol in a $80^{\circ} \mathrm{C}$ water bath for $30 \mathrm{~min}$ to extract the soluble sugars. The ethanol was decanted, the tissues were pelleted by centrifugation at $4200 g_{n}$ for $5 \mathrm{~min}$ in a centrifuge (model 5403; Eppendorf, Hamburg, Germany) and then reextracted three more times as above. A 4- to 6-mL portion of the pooled ethanol extract was taken to dryness in a concentrator (SpeedVac; SAVANT, Farmingdale,
N.Y.). Dried samples were resuspended in $1 \mathrm{~mL}$ deionized water, deionized on coupled $1 \mathrm{~mL}$ anion and cation resin columns (AG1X8/formate and AG50W-X8/H+, BIO-RAD, Hercules, Calif.) and analyzed using an isocratic high-performance liquid chromatograph (HPLC) equipped with a refractive index detector using an anion-exchange column (Sugar-Pak I; Waters, Milford, Mass.) as described previously (Liu et al., 1999a; Madore, 1990). Nectar samples were deionized and analyzed by HPLC as above. Starch remaining in the extracted tissue was analyzed by a hexokinase reaction after amyloglucosidase treatment as described previously (Liu et al., 1999a).

Phloem SaP Analysis. The experimental protocol for phloem exudate collection was essentially that described previously for olive (Olea europeae L.) tree samples (Flora and Madore, 1993). Excised shoots taken from the field were equilibrated under a waterfiltered light source (Plant Gro and Show; General Electric Co., Bridgeport, Conn., $300 \mu \mathrm{mol} \cdot \mathrm{m}^{-2} \cdot \mathrm{s}^{-1}$ of photosynthetically active radiation) for $30 \mathrm{~min}$. The entire shoot was then enclosed in a plastic bag and allowed to photosynthetically assimilate $3.7 \times 10^{5} \mathrm{~Bq}$ of ${ }^{14} \mathrm{CO}_{2}$ for a $30 \mathrm{~min}$ period (Flora and Madore, 1993; 1996). Five mature leaves were then excised from the shoots by immersing the shoots in water and cutting off the leaves at the base of the petiole with a razor blade. The cut end of the petiole was immersed immediately into $20 \mathrm{~mm} \mathrm{Na} \mathrm{N}_{2}$ EDTA, $\mathrm{pH} 7.0$, in a petri dish and the petiole was recut at an angle leaving a stub of a standard 2- to 3-mm length attached to the leaf base. The petiole stub was immersed in a 1.5-mL microfuge tube filled with $20 \mathrm{~mm} \mathrm{Na}{ }_{2}$ EDTA, $\mathrm{pH}$ 7.0, solution. The excised leaves were then placed in a transparent plastic box lined with moist paper towel, the lid of the box was closed to reduce transpiration, and phloem sap exudation was allowed to proceed under ambient room light and temperature conditions. Phloem exudate was collected at 3 -h intervals for $12 \mathrm{~h}$ by replacing the microcentrifuge tubes with the fresh tubes containing $\mathrm{Na}_{2}$ EDTA solution. The contents of the microfuge tubes were then deionized as above, the sugars were eluted from the columns with $7 \mathrm{~mL}$ deionized water, taken to dryness in the concentrator, redissolved in $75 \mu \mathrm{L}$ water, filtered $(0.45-\mu \mathrm{m}$ pore size), and analyzed by HPLC as above. Radioactivity in individual sugars was determined by collecting the detected peaks using a fraction collector followed by scintillation counting of the collected fractions (Flora and Madore, 1993, 1996).

Production of C7 Sugars by Cell-Free extracts from MaTURE SOURCE LEAVES. Three short shoots bearing several mature leaves were removed from a tree using a razor blade and the cut ends immersed in a beaker of water for transfer from the field to the laboratory . The leaves were then excised from the shoots, cleaned with a moist tissue, and the midribs removed. The remaining tissue $(\approx 2 \mathrm{~g})$ was then frozen in liquid $\mathrm{N}_{2}$. All subsequent extraction procedures were performed either on ice or at $4{ }^{\circ} \mathrm{C}$.

Frozen tissues were ground quickly in a mortar and pestle in $8 \mathrm{~mL}$ chilled extraction buffer (100 mM MOPS-NaOH, pH 7.5; $10 \mathrm{~mm}$ DTT; 10 mm ascorbic acid; $5 \mathrm{~mm} \mathrm{MgCl}_{2} ; 0.5 \mathrm{~mm} \mathrm{Na} 2 \mathrm{EDTA} ; 1 \%$ (v/ v) Triton-X100) plus 5\% (w/v) insoluble PVPP. The extract was filtered through two layers of cheesecloth then centrifuged for $1 \mathrm{~min}$ at $800 \mathrm{~g}_{\mathrm{n}}$. One milliliter of supernatant was desalted through a $1.8 \times$ $12 \mathrm{~cm}$ Sephadex G-25 (fine: 20 to $80 \mu \mathrm{m}$ ) column equilibrated with $100 \mathrm{~mm}$ MOPS buffer, pH 7.5 containing $10 \mathrm{~mm}$ DTT and $5 \mathrm{~mm}$ $\mathrm{MgCl}_{2}$. Protein content of the desalted extract was determined with Coomassie Blue (Bradford, 1976) using bovine serum albumin as a standard.

D-MANNOHEPTULOSE-P BIOSYNTHESIS ASSAY. Typically, the assay mixture contained $30 \mathrm{~mm}$ Tris-HCl buffer, $\mathrm{pH} 7.5 ; 5 \mathrm{~mm}$ DTT and 
$1 \mathrm{~mm} \mathrm{MgCl}_{2} ; 20$ mm substrates (erythrose-4-P plus dihydroxyacetone-P, or ribose-5-P plus xylulose-5-P, respectively) and desalted enzyme in a total volume of $150 \mathrm{~mL}$ in $1.5-\mathrm{mL}$ microfuge tubes. Tubes were capped and incubated in a shaking water bath at $33^{\circ} \mathrm{C}$ for 30 to $60 \mathrm{~min}$ then the reaction was stopped by placing the tubes in a boiling water bath for $1 \mathrm{~min}$. Three units of acid phosphatase, dissolved in $200 \mathrm{~mL}$ of $100 \mathrm{~mm}$ sodium acetate buffer, $\mathrm{pH} 4.5$, was added to each tube and the tubes were reincubated in a shaking water bath at $37^{\circ} \mathrm{C}$ for $3 \mathrm{~h}$ to convert the sugar phosphates to free $\mathrm{C} 7$ sugars.

Sedoheptulose and D-mannoheptulose were not separated by the Sugar-Pak HPLC protocols commonly employed in this laboratory and so paper chromatography was used to separate these two C7 sugars before quantification. The contents of the enzyme assay tubes were deionized through $1 \mathrm{~mL} 200$ - to 400 mesh anion and cation resin columns (AG-1-8X/formate and AG$50 \mathrm{~W} / \mathrm{H}+$, Bio-Rad, Hercules, Calif.), eluted with $7 \mathrm{~mL}$ deionized water, taken to dryness in a concentrator, redissolved in $30 \mathrm{~mL}$ deionized water, and filtered through a $0.45-\mathrm{mm}$ syringe filter. Duplicate aliquots $(15 \mathrm{~mL})$ of each filtrate were then applied to Whatman No. 1 filter paper sheets and the chromatograms were run in descending mode in $7 \mathrm{n}$-propanol : 1 ethyl acetate : 2 deionized water (by volume) for 24 to $40 \mathrm{~h}$.

After development, each assay lane was excised and all lanes corresponding to the first aliquot from each assay were treated with orcinol reagent spray $(0.5 \mathrm{~g}$ orcinol, $15 \mathrm{~g}$ trichloroacetic acid in 100 $\mathrm{mL}$ water-saturated n-butanol) sprayed, then heated at $100^{\circ} \mathrm{C}$ for 15 min) which produces unique blue and blue-green colors with sedoheptulose and D-mannoheptulose respectively (Bevenue and Williams, 1951; Williams et al., 1952). Mannoheptulose and sedoheptulose were identified by comparison to known standards also run on the same chromatograms. To obtain quantitative data, the unsprayed lanes corresponding to the second aliquots from each assay tube were then lined up with their sprayed counterparts and the areas on the lane matching up in position with the orcinol spots were excised, cut into strips, and placed in flasks containing $15 \mathrm{~mL} \mathrm{50 \%}$ $(\mathrm{v} / \mathrm{v})$ ethanol to elute the separated sugars. The eluate was filtered through a 0.8 -mm filter to remove any paper lint residues, taken to dryness in the Speed Vac Concentrator and redissolved in $80 \mu \mathrm{L}$ deionized water. Quantification of the isolated sedoheptulose or mannoheptulose was then carried out by HPLC as above by comparison to authentic standards.

Fruit RIPENING EXPERIMENTS. Avocado fruit were harvested during the commercial harvest season and stored in commercial storage bins at the University of California Kearney Agricultural Field Station, Parlier, Calif., under environmental conditions $\left(20^{\circ} \mathrm{C}\right.$ and $85 \%$ to $90 \%$ relative humidity) that would induce normal ripening over $12 \mathrm{~d}$. Each day following harvest, 15 to 20 fruit were weighed and then investigated for ripening parameters including loss of firmness, respiration rate $\left(\mathrm{CO}_{2}\right.$ production), and ethylene production.

Before measuring respiration and ethylene production, individual fruit were sealed in a cylindrical plastic 0.88 - $\mathrm{L}$ container for 1 to $3 \mathrm{~h}$. Two 12-mL gas samples were then withdrawn from the container into plastic syringes. For ethylene determination, one gas sample was injected into a gas chromatograph (Series 400 AGC 211-2; EG\&G Chandler, Broken Arrow Okla.) equipped with two $8 \% \mathrm{NaCl}$ on alumina F- 1 columns $(0.32 \times 122 \mathrm{~cm}$ and $0.32 \times 30 \mathrm{~cm}$, $80 / 100$ mesh $)$ and one molecular sieve 5 A column $(0.32 \times 91 \mathrm{~cm}$, $80 / 100 \mathrm{Mesh}$ ) and a flame ionization detector. Separations were performed at $70{ }^{\circ} \mathrm{C}$ and a flow rate of $60 \mathrm{~mL} \cdot \mathrm{min}^{-1}$ using a flow gas mixture consisting of hydrogen $(220 \mathrm{kPa})$, compressed air $(83 \mathrm{kPa})$ and helium $(248 \mathrm{kPa})$ and a sample injection volume of $2.0 \mathrm{~mL}$. For measurement of respiratory $\mathrm{CO}_{2}$ production, the other gas sample was injected into a gas chromatograph (series AGC-111; EG\&G Chandler) equipped with a HayeSep A column $(0.32 \times 152 \mathrm{~cm}, 60 /$ $80 \mathrm{mesh})$, a molecular sieve $13 \times$ column $(0.32 \times 213 \mathrm{~cm}, 80 / 100$ mesh), and $8 \%$ OV- 101 on a Chromosorb WHP column $(0.32 \times 183$ $\mathrm{cm}, 80 / 100 \mathrm{mesh}$ ) and a thermal conductivity detector (thermistor current $=20 \mathrm{~mA}$ ). Separations were performed at $70^{\circ} \mathrm{C}$ and a flow rate of $30 \mathrm{~mL} \cdot \mathrm{min}^{-1}$ using helium $(414 \mathrm{kPa})$ as a flow gas and a sample injection volume of $1.0 \mathrm{~mL}$.

Following the gas exchange measurements, a small piece of the exocarp (skin) of the fruit was removed on opposite sides of the fruit at the widest point (about two-thirds of the distance from the stem end). The penetration force required to puncture the fruit flesh was then measured using a University of California firmness tester fitted with a 7-mm tip. For carbohydrate analysis, a longitudinal slice, weighing $\approx 12 \mathrm{~g}$, was taken from each fruit and the flesh was separated from its peel and seed. The flesh slice was weighed immediately, cut into small pieces, freeze-dried, and processed for carbohydrate analysis as described above.

FrUIT GIRDLING EXPERIMENTS. In late Feb. 1999, when fruit were mature, 10 to 15 fruit were tagged randomly from each of 6 selected adjacent trees. Five or six tagged fruit were girdled on their fruit stalks, $\approx 2 \mathrm{~cm}$ from the proximal end of the fruit, by removal of a 2 to $3 \mathrm{~mm}$ strip of bark using a razor blade and a small lab spatula. This

Table 1. Carbohydrate composition of source leaves and vegetative and reproductive sink tissues of the avocado tree. Samples were collected at midday during 2 weeks in April 1996 from trees growing in a field plot in Irvine, Calif.

\begin{tabular}{|c|c|c|c|c|c|c|}
\hline \multirow[b]{2}{*}{$\begin{array}{l}\text { Plant } \\
\text { tissue }\end{array}$} & \multicolumn{6}{|c|}{ Carbohydrate $\left(\mathrm{mg} \cdot \mathrm{g}^{-1} \text { dry wt }\right)^{z}$} \\
\hline & Starch & Sucrose & Hexoses & $\begin{array}{l}\text { Mannohep- } \\
\text { tulose }\end{array}$ & Perseitol & $\begin{array}{c}\text { C7 sugar } \\
\text { as } \% \text { of total }\end{array}$ \\
\hline Leaf mature & $49.9 \pm 12.6$ & $38.0 \pm 6.8$ & $30.0 \pm 3.3$ & $70.4 \pm 12.8$ & $174.0 \pm 6.4$ & 67.5 \\
\hline Leaf immature & $28.8 \pm 4.9$ & $29.8 \pm 4.9$ & $87.4 \pm 1.5$ & $57.8 \pm 6.3$ & $139.0 \pm 8.9$ & 57.4 \\
\hline Trunk, cambium & $38.9 \pm 3.6$ & $9.9 \pm 1.6$ & $8.1 \pm 0.8$ & $12.4 \pm 0.6$ & $67.6 \pm 3.2$ & 58.4 \\
\hline Shoot, stem & $70.5 \pm 5.9$ & $15.0 \pm 0.8$ & $7.7 \pm 1.9$ & $36.9 \pm 3.1$ & $111.0 \pm 8.8$ & 61.3 \\
\hline Root & $41.1 \pm 11.6$ & $7.4 \pm 2.3$ & $7.8 \pm 1.5$ & $47.1 \pm 4.3$ & $78.7 \pm 5.6$ & 69.1 \\
\hline Flower, pistil & $20.0 \pm 8.5$ & $109.8 \pm 47.7$ & $77.0 \pm 21.0$ & $24.7 \pm 10.9$ & $23.1 \pm 10.5$ & 18.8 \\
\hline Flower, stamen & $32.2 \pm 2.0$ & $177.6 \pm 10.8$ & $106.0 \pm 7.4$ & $27.8 \pm 2.0$ & $30.6 \pm 2.0$ & 15.6 \\
\hline Flower, nectar & --- & $347.0 \pm 38.3$ & $77.4 \pm 13.3$ & $16.2 \pm 3.7$ & $23.6 \pm 4.7$ & 8.6 \\
\hline Fruit, flesh & $9.2 \pm 2.4$ & $19.3 \pm 2.0$ & $9.7 \pm 2.2$ & $25.6 \pm 7.1$ & $29.2 \pm 2.3$ & 58.9 \\
\hline Fruit, peel & $14.0 \pm 1.6$ & $8.6 \pm 0.6$ & $0.3 \pm 0.1$ & $22.3 \pm 0.5$ & $124.0 \pm 6.6$ & 86.5 \\
\hline Fruit, seed & $246.1 \pm 20.1$ & $18.5 \pm 3.2$ & $1.9 \pm 0.7$ & $63.8 \pm 0.6$ & $88.3 \pm 8.1$ & 36.3 \\
\hline
\end{tabular}

${ }^{\mathrm{z}}$ Mean of six measurements \pm SE. 

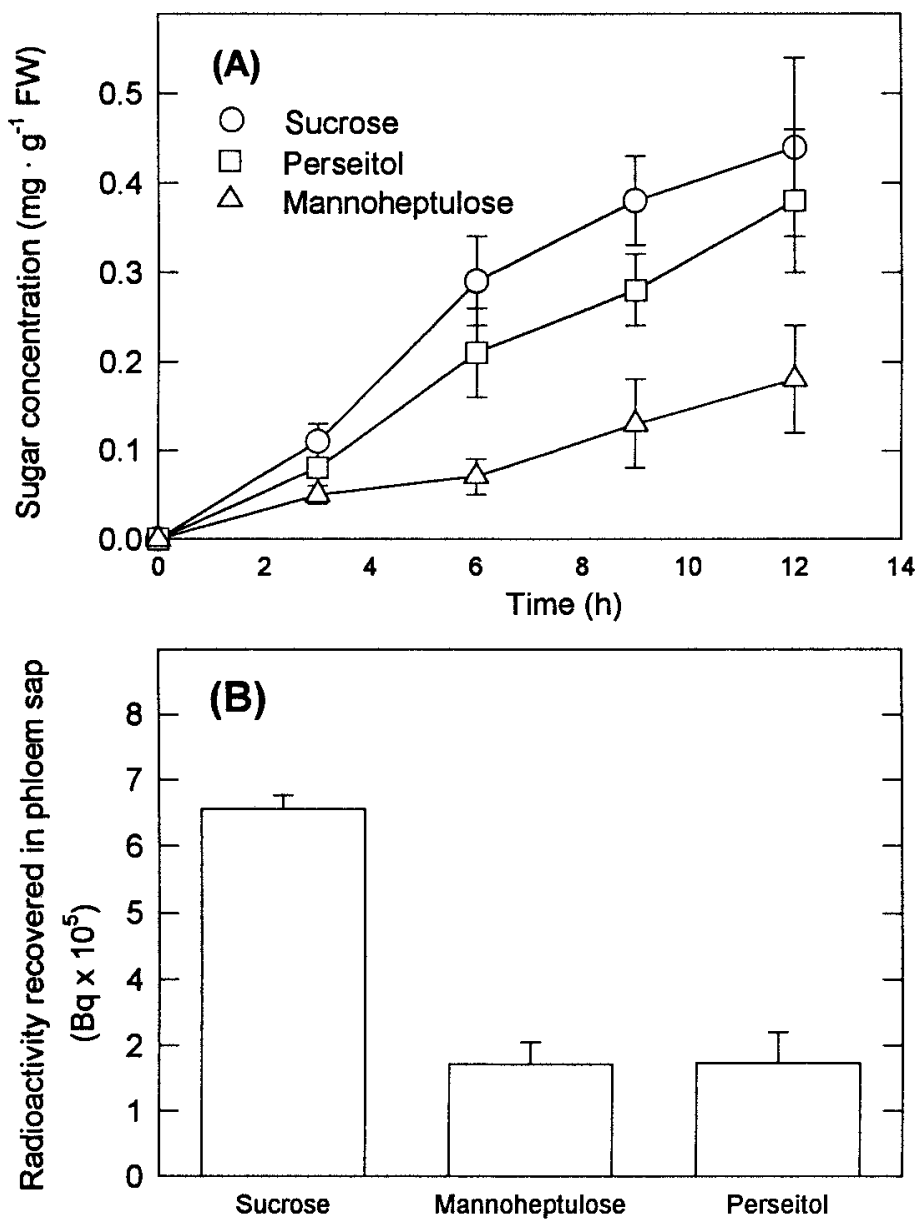

Fig. 2. Sugar composition of phloem sap exudates obtained from avocado source leaves. (A) Cumulative sugar exudation over time) and (B) radioactivity in individual sugars after $12 \mathrm{~h}$ exudation following pulse-labelling of detached leaves with ${ }^{14} \mathrm{CO}_{2}$. Vertical bars represent $\pm 1 \mathrm{sE}, \mathrm{n}=6$.

procedure was repeated again on another set of five to six tagged fruit from each tree 2 weeks later, in early March, 1999. Mesh bags were used to support the girdled fruit which tended to abscise as they softened and ripened on the trees. After 1 month from the first girdling, the tagged fruit were harvested and transported in a thermal insulated ice chest to the laboratory where they were stored overnight at $4{ }^{\circ} \mathrm{C}$ before analysis of ripeness and carbohydrate content.

Fruit were rated with a numerical scale of 0 to 7 for degree of ripeness by the method of hand firmness as follows (White et al., 1998): 0 = overripe, flesh feels almost liquid; $1=$ very ripe, whole fruit deforms with slight hand pressure; 2 = fully ripe, whole fruit deforms with moderate hand pressure; $3=$ deformation achieved with very little finger pressure; $4=$ can feel 2 to $3 \mathrm{~mm}$ deformation with moderate finger pressure; $5=$ very rubbery, can feel the flesh deform under extreme finger force; $6=$ slight give such that it feels rubbery; and 7 = very hard, no give in the fruit.

The sugar and starch content of samples excised from the fruit tissues were then analyzed as described above for the picked and stored fruit.

\section{Results}

C7 SUgar CONTENT OF SOURCE AND SINK TISSUES. With the exception of the floral organs and nectar, C7 sugars represented the predominant forms of nonstructural carbohydrate in the avocado tissues analyzed (Table 1). In source leaf tissues, the contribution of the $\mathrm{C} 7$ sugars to the total carbohydrate profile greatly exceeded that of the conventional six-carbon (C6) hexose-based sugars (starch, sucrose, and hexoses), with the polyol form, perseitol, being present at the highest concentration. In vegetative sink tissues (immature leaves, roots, trunk, and stems) and in fruit flesh and peel the same general trend was observed. Only in floral organs (stamens and pistils) and nectar were levels of six-carbon sugars, most notably sucrose, higher than the $\mathrm{C} 7$ sugars. In the seed, starch accounted for most of the total nonstructural carbohydrate.

Phloem mobility of the C7 Sugars. Detached avocado source leaves exuded sugars from their petioles into Na-EDTA solutions (Fig. 2). The predominant sugars were sucrose and perseitol which were present at close to equal amounts throughout the exudation period on a milligram basis (Fig. 2A). On a molar basis, perseitol [molecular weight $(\mathrm{MW})=212$ ] was present at a higher concentration than sucrose (MW = 342). Mannoheptulose was also detected in amounts about half those of the other two sugars (Fig. 2A).

When leaves were photosynthetically labeled with ${ }^{14} \mathrm{CO}_{2}$ before detachment, all three sugars in the exudation solution were labeled with ${ }^{14} \mathrm{C}$ (Fig. 2B). The amount of label recovered in sucrose was $\approx 3$-fold higher than that recovered in the $\mathrm{C} 7$ sugars, which were approximately equally labeled (Fig. 2B).

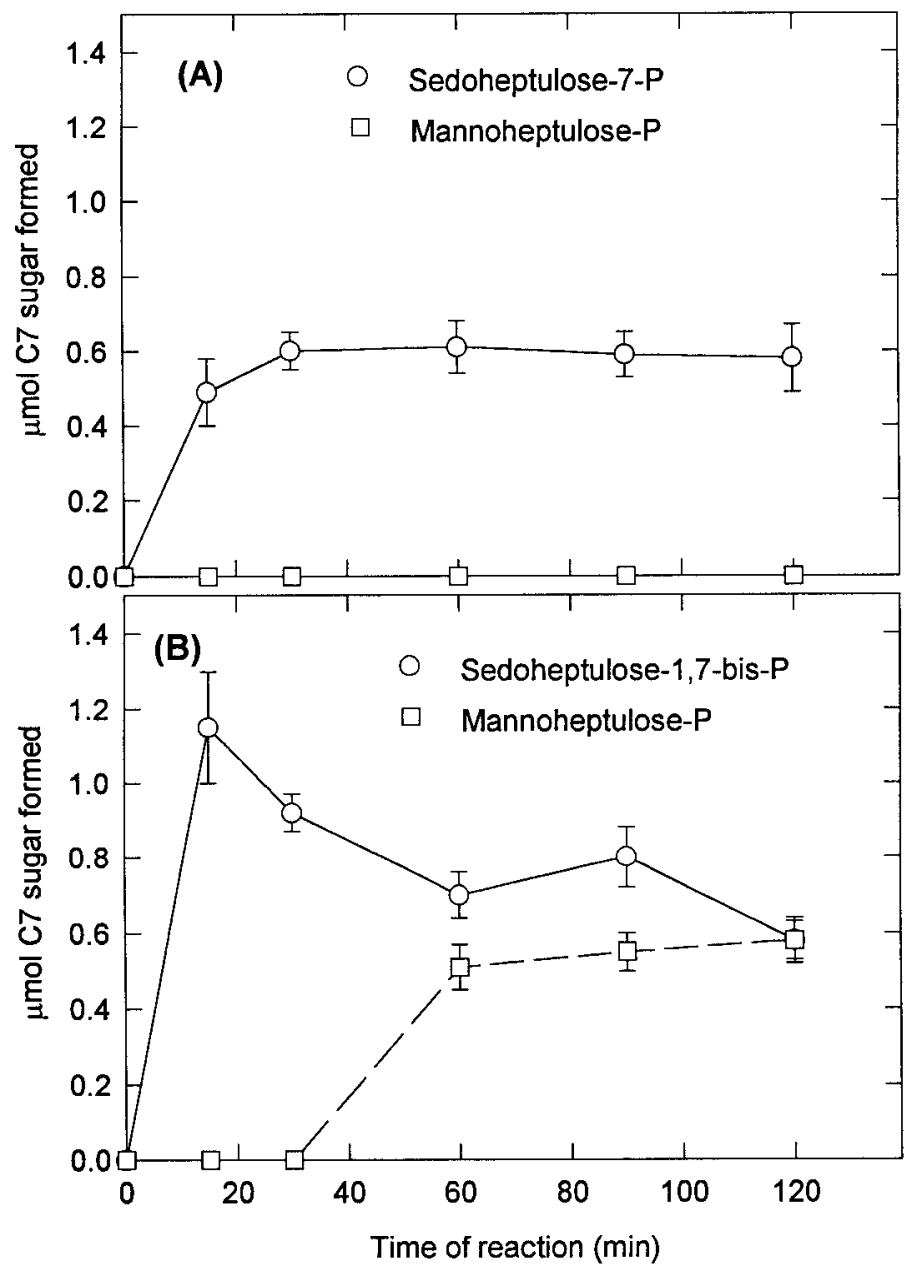

Fig. 3. Seven-carbon sugar phosphate formation by cell-free extracts from avocado source leaves. (A) Extracts assayed with transketolase substrates (xylulose-5-P plus ribose-5-P) and (B) extracts assayed with aldolase substrates (erythrose-4-P plus dihydroxyacetone-P). Vertical bars represent $\pm 1 \mathrm{sE}, \mathrm{n}=3$. 
FORMATION OF MANNOHEPTULOSE BY SOURCE LEAF EXTRACTS. Cell-free extracts from mature avocado source leaves produced sedoheptulose-7-P(Fig. 3A) or sedoheptulose-1,7-bis-phosphate from transketolase (Fig. 3A) and aldolase (Fig. 3B) substrates respectively. However, only the aldolase product, sedoheptulose1,7-bis-P, was converted further to mannoheptulose (Fig. 3B). Phosphorylated intermediates were involved as evidenced by the need to treat assay products with a phosphatase in order to detect any C7 sugars, including mannoheptulose (data not presented).

Carbohydrate Changes duRING FrUIT RIPENING. After $5 \mathrm{~d}$ of storage at $20^{\circ} \mathrm{C}$, mature fruit began to ripen, as noted by a decrease in fruit firmness. Ripening fruit showed an increase in respiration (Fig. 4A) and an increase in ethylene evolution (Fig. 4B). In mature, unripened fruit, perseitol represented the primary form of carbohydrate at levels of $\approx 30 \mathrm{mg} \cdot \mathrm{g}^{-1}$ dry weight (DW) (Fig. 4C). Levels of mannoheptulose remained at low but measurable levels throughout the ripening process (Fig. 4D). In unripe fruit, perseitol levels $\left(30 \mathrm{mg} \cdot \mathrm{g}^{-1} \mathrm{DW}\right)$ greatly exceeded those of sucrose or its component hexoses, glucose, and fructose (Fig. 4E) or of starch (Fig. 4F). The ripening process was accompanied by increases in
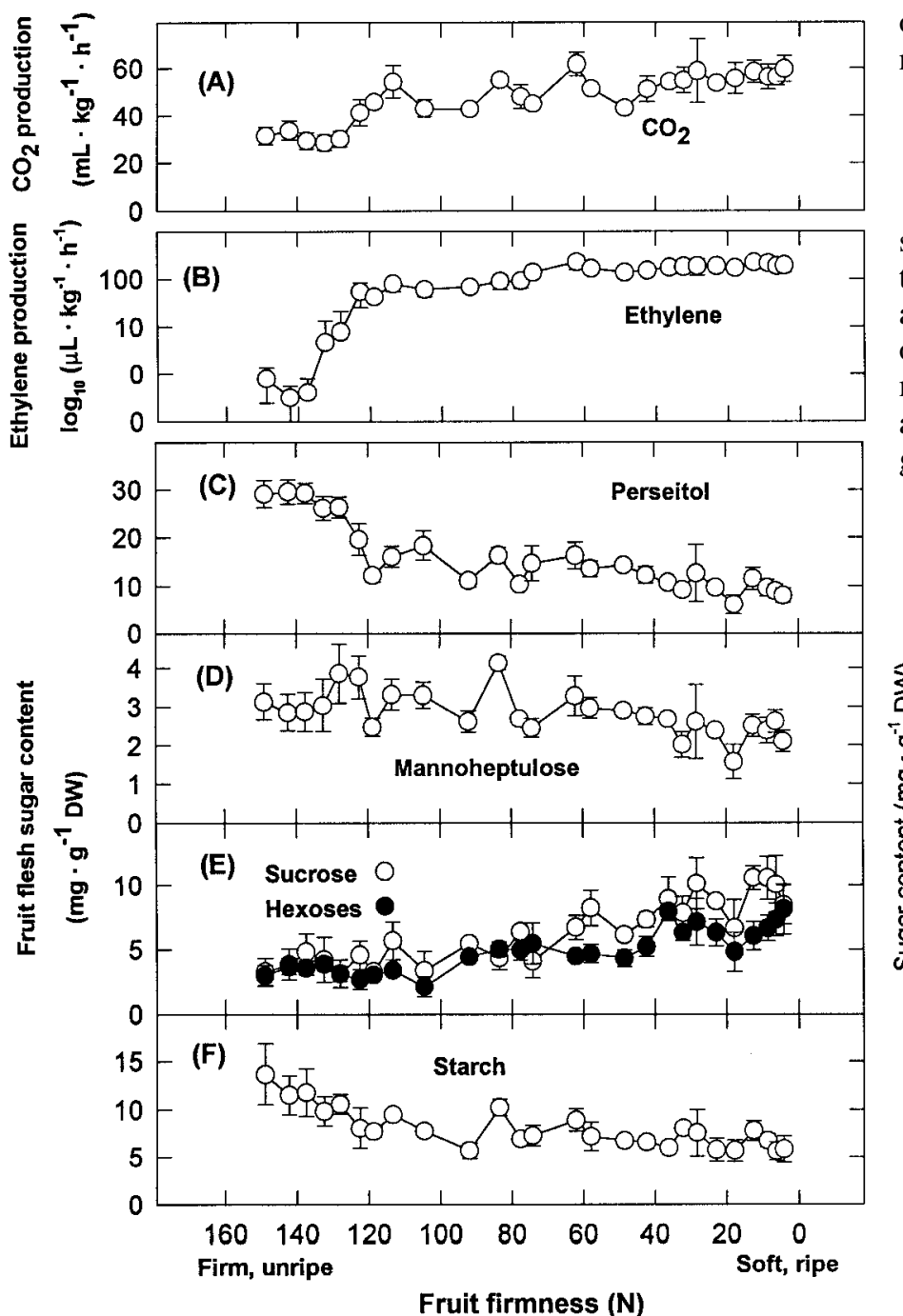

Fig. 4. Avocado fruit ripening and sugar composition during storage at $20^{\circ} \mathrm{C}$ and $85 \%$ relative humidity. Physiological changes associated with ripening such as (A) respiration and (B) ethylene release were monitored along with changes in (C) perseitol, (D) mannoheptulose, (E) sucrose and hexoses, and (F) starch in the ripening fruit flesh. Vertical bars represent $\pm 1 \mathrm{sE}, \mathrm{n}=12$. the hexose-based sugars, particularly sucrose (Fig. 4E), while the content of perseitol (Fig. 4C) and starch (Fig. 4F) declined substantially. Levels of perseitol in fully ripened fruit declined to levels below those of sucrose and hexoses, which then represented the primary forms of sugar in the flesh (combined value $\approx 20 \mathrm{mg} \cdot \mathrm{g}^{-1} \mathrm{DW}$, Fig. 4E).

FRUIT CARBOHYDRATE CHANGES AFTER PHLOEM GIRDLING. About $30 \mathrm{~d}$ after girdling of the fruit stalk, fruit still attached to the tree had a range of stages of ripeness as measured by firmness (Fig. 5), including many with fully ripe ratings of 1 to 2 . Nongirdled fruit, on the other hand, maintained a firmness rating of 7 or the fully unripe state (Fig. 5). Cross sections of the fruit stalk showed that the xylem tissues of girdled stalks remained intact and undamaged, thus presumably functional (data not presented), suggesting that girdling had only affected phloem transport into the fruit. Thus, the first effect of this blockage of phloem translocation appeared to be removal of the ripening inhibition which normally occurs when fruit remain attached to the tree. Nongirdled (unripe) fruit had the highest levels of C7 sugars (both perseitol, Fig. 5A, and mannoheptulose, Fig. 5B) in their flesh. Girdled (ripe or ripening) fruit contained substantially lower levels of $\mathrm{C} 7$ sugars (Fig. 5A and B) while levels of six-carbon sugars were not substantially different between nongirdled and girdled fruit (Fig. 5C).

\section{Discussion}

Data presented herein further corroborate and extend our past studies (Liu et al., 1999a, 1999b) which demonstrated the importance of the $\mathrm{C} 7$ sugars in carbon allocation processes in the avocado tree. It is evident from these data that $\mathrm{C} 7$ sugars are not only important storage reserves in the tree but are also phloem mobile products of primary $\mathrm{CO}_{2}$ fixation. More importantly, they apparently contribute to the carbon balance of the plant to a greater extent than the more conventional C6 sugars, as was

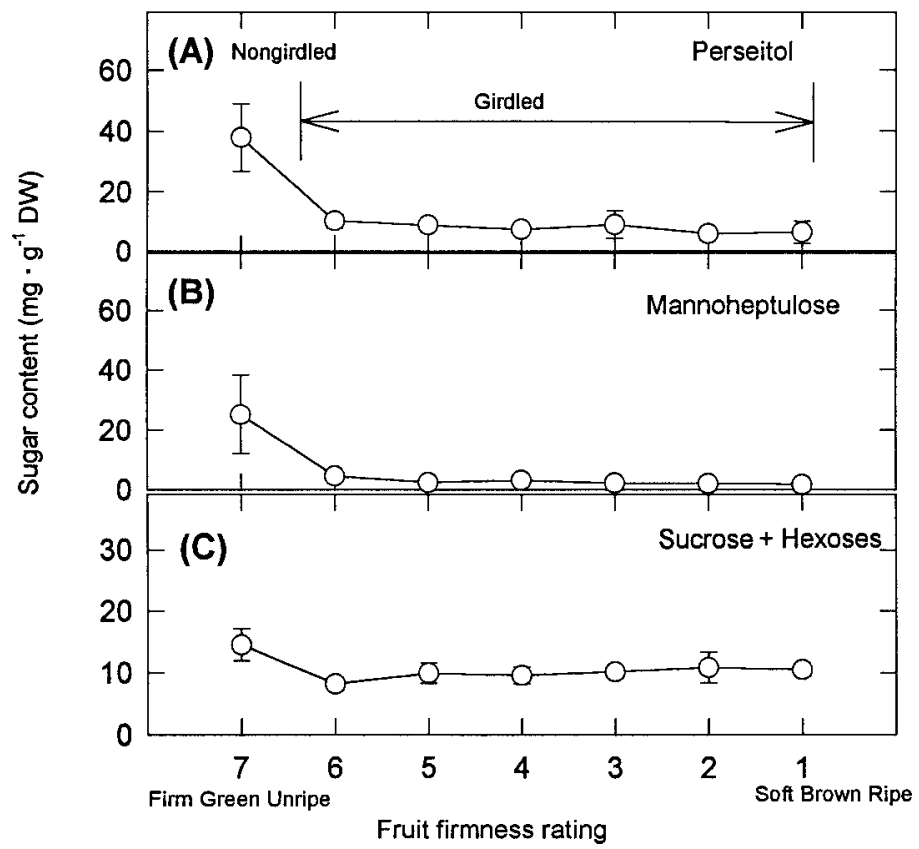

Fig. 5. Changes in fruit sugar composition in avocado fruit induced to ripen on the tree by girdling the fruit stalk. (A) Fruit perseitol concentration vs. degree of ripeness, (B) fruit mannoheptulose concentration vs. degree of ripeness, and $(\mathbf{C})$ fruit six-carbon sugar concentrations vs. degree of fruit ripeness. See text for description of ripeness scale of White et al., 1999. Vertical bars represent $\pm 1 \mathrm{sE}, \mathrm{n}=12$. 
evident from the phloem sap analysis, where molar amounts of perseitol were higher than those of sucrose. This is in contrast to what has been previously reported in hybrid polyanthus (Primula ×polyantha Hort.) for volemitol, another phloem-mobile C7 sugar, (Häfliger et al., 1999) whose levels in phloem exudates were substantially lower (only about one-quarter the concentration) than those of sucrose. Interestingly though, the reducing form of $\mathrm{C} 7$ sugar, sedoheptulose, corresponding to the $\mathrm{C} 7$ polyol volemitol was also found in phloem exudates, as we have found in the present study for mannoheptulose.

The presence of mannoheptulose and sedoheptulose in phloem exudates is intriguing, as common dogma holds that reducing sugars are excluded from the phloem as they may elicit unfavorable Amadori-type reactions with proteins (Arnold, 1968). Thus, it is thought that reducing sugars are metabolized into more complex nonreducing forms such as di- and oligosaccharides and polyols to prevent this type of interaction, although these types of interactions have not been documented in vivo. An alternative view is that nonreducing forms simply represent a means of preventing metabolism of phloem-mobile carbon within the cytoplasmic milieu of the sieve element. By restricting the enyzmes for conversion of nonreducing forms back to free reducing sugars to tissues outside the sieve elements, the metabolism of phloem-mobile sugar by the sieve elements themselves is prevented. Thus, the nonreducing sugars are thought to act as protected derivatives of glucose (Arnold, 1968) and we suggest that the reducing forms of the $\mathrm{C} 7$ sugars may represent a similar strategy. As indicated previously, there are very few biochemical pathways in which seven-carbon sugars are intermediates, and in the few in which they are found, they are always in the form of a sugar-phosphate. This implies that in order for a $\mathrm{C} 7$ reducing sugar to be put back into general metabolism, it must be phosphorylated and then enter a metabolic pathway which can use a C7 skeleton. If the sieve element lacks the enzymology for phosphorylation or further metabolism, then the $\mathrm{C} 7$ reducing sugars may also be operating as protected derivatives of glucose. This idea warrants further study.

A second key finding is that the $\mathrm{C} 7$ seven-carbon backbone may arise from the Calvin Cycle reactions. Clearly, avocado source leaves were capable of forming radiolabeled $\mathrm{C} 7$ sugars, which collected in the phloem exudate. Our data from the cellfree extracts show that sedoheptulose-1,7-bis-phosphate was a suitable precursor for the production of mannoheptulose-P, whereas sedoheptulose-7-P was not. This strongly suggests that an aldolase reaction similar to that of the Calvin Cycle is the source of the $\mathrm{C} 7$ backbone, but the exact cellular location of the enzyme activity which converts sedoheptulose-1,7-bis-P to mannoheptulose-P, or indeed the nature of the phosphorylated mannoheptulose (mono- or bis-P) remains to be established. We were unable to detect, during our assay protocol, any direct conversion of the phosphorylated form to the free sugar, which may simply mean that our assay conditions were not right for activity of the phosphatase that carries out this reaction in vivo. Similarly, we saw no production of perseitol, which again may suggest that dephosphorylation to the free sugar precedes the reduction step, as occurs for volemitol synthesis in polyanthus (Häfliger et al., 1999).

Data presented herein also suggest that C7 sugar metabolism may be an important feature of the fruit-ripening process. Clearly, in the unripened fruit, perseitol was the predominant form of soluble sugar and its levels declined substantially as the ripening process progressed. In fact, in the girdling experiment, a distinct correlation appeared to exist between the induction of ripening (i.e., the transition from Stage 7 toward Stage 6 fruit) and the loss of perseitol and mannoheptulose in the fruit. As long as C7 sugar levels remained above a threshold of $\approx 20 \mathrm{mg} \cdot \mathrm{g}^{-1} \mathrm{DW}$, no ripening was evident. The same correlation was seen in the picked fruit ripened at $20{ }^{\circ} \mathrm{C}$, where the normal physiological events such as ethylene production and increased respiration associated with the onset of ripening were not initiated until a drop in C7 sugar levels below $\approx 20 \mathrm{mg} \cdot \mathrm{g}^{-1} \mathrm{DW}$ had also occurred. This may indicate that the ripening process is associated with catabolism of $\mathrm{C} 7$ sugars but it is equally possible that the $\mathrm{C} 7$ sugars themselves may be controlling the ripening process. Further data from other seasons and for other cultivars are needed to resolve these issues.

It has long been presumed that avocado fruit do not ripen on the tree due to a ripening inhibitor which is transported from the tree to the fruit, but the nature of this ripening inhibitor has remained elusive. We hypothesize that the $\mathrm{C} 7$ sugars may be partly responsible for ripening inhibition, based on the data presented herein. First, the C7 sugars are clearly phloem-mobile, making them potential candidates for mobile inhibitors. Second, manno-heptulose is a very potent inhibitor of respiratory processes, acting as a hexokinase inhibitor and preventing input of glucose into the glycolytic cycle (Board et al., 1995). As such, mannoheptulose, or a C7 sugar form which can be converted to mannoheptulose (which perseitol may be), would be an ideal candidate for suppressing the ripening process, which involves a massive increase in fruit respiration. Third, the ripening process was clearly inhibited until C7 sugars were metabolized to below a certain level in the fruit, although more data are required to establish the postulated threshold. And fourth, although it has been presumed that plant hormones participate in the control of avocado fruit ripening (Cowan et al., 2001; Tingwa and Young, 1975a, 1975b), there is increasing evidence for sugars having major roles in plant developmental processes (as discussed by Cowan et al., 2001). Such may also be the case for $\mathrm{C} 7$ sugars in avocado.

Previous reports (Tingwa and Young, 1975a, 1975b) failed to demonstrate any effect of phloem-girdling on the ability of avocado fruit to ripen on the tree. These reports also indirectly support the role of the $\mathrm{C} 7$ sugars in the control of ripening, as in their case girdling was done, not on the fruit stalks, but on the stems connecting the fruit with the leaves. The aim of this latter type of girdling was to prevent leaf-derived inhibitors from being translocated to the fruit and it was concluded that no leaf-derived substances, either sugars or hormones, were involved in ripening inhibition. We therefore suggest that the stems themselves (as seen in Table 1) may have represented substantial sources of stored C7 sugars. These could have been mobilized into the fruit via phloem transport, keeping the $\mathrm{C} 7$ sugar levels high in the fruit and thus inhibiting ripening over the experimental period measured in these studies.

In conclusion, our results clearly indicate that $\mathrm{C} 7$ sugars, and in particular the polyol form, perseitol, are major phloem-mobile sugars in avocado. These sugars are primary products of photosynthesis and may be derived via mechanisms which divert carbon directly from the Calvin Cycle following the aldolase reaction that produces sedoheptulose-1,7-bis-P. The C7 sugars can therefore be viewed as major contributors to the carbon balance of the avocado tree and appear to function as stored reserves in all vegetative storage sinks. It is also possible that transport of $\mathrm{C} 7$ sugars to the fruit is part of the mechanism which inhibits fruit ripening on the tree in this species, in association with hormone homeostasis and signalling. 


\section{Literature Cited}

Arnold, W.N. 1968. The selection of sucrose as the translocate of higher plants. J. Theor. Biol. 21:13-20.

Bean. R.C., G.G. Porter, and B.K. Barr. 1963. Carbohydrate metabolism of avocado. II. Formation of sugars during short periods of photosynthesis. Plant Physiol. 38:280-284.

Begbie, R. and N.K. Richtmyer. 1966. The isolation of some heptoses, heptuloses, octuloses, and nonuloses from Primula officinalis Jacq. Carbohydrate Res. 2:272-288.

Bevenue, A., L.M. White, G.E.Secor, and K.T. Williams. 1961. The occurrence of two heptuloses in the fig plant. J. Assn. Offic. Agr. Chemists 44:265-266.

Bevenue, A. and K.T. Williams. 1951. Further evidence indicating the specificity of the orcinol spray reagent for ketoheptoses on paper chromatograms. Arch. Biochem. Biophys. 34:225-227.

Board, M., A. Colquhoun, and E.A. Newsholme. 1995. High K glucosephosporylating (glucokinase ) activities in a range of tumor cell lines and inhibition rates of tumor growth by the specific enzyme inhibitor mannoheptulose. Cancer Res. 55:3278-3285.

Bowyer, J.R. and R.C. Leegood. 1997. Photosynthesis, p. 49-110. In: P.M. Dey and J.B. Harborne (eds.). Plant biochemistry. Academic Press, San Diego.

Bradford, M.M. 1976. A rapid and sensitive method for the quantitation of microgram quantities of protein utilizing the principle of protein-dye binding. Anal. Biochem. 72:248-254.

Brownleader, M.D., J.B. Harborne, and P.M. Dey. 1997. Carbohydrate metabolism: Primary metabolism of monosaccharides, p. 111-142. In: P.M. Dey and J.B. Harborne (eds.). Plant biochemistry. Academic Press, San Diego.

Cowan, A.K., R.F. Cripps, E.W. Richings, and N.J. Taylor. 2001. Fruit size: Towards an understanding of the metabolic control of fruit growth using avocado as a model system. Physiol. Plant. 111:127-136.

Flora L.L. and M.A. Madore. 1993. Stachyose and mannitol transport in olive (Olea europaea L.). Planta 189:484-490.

Flora L.L. and M.A. Madore. 1996. Significance of minor-vein anatomy to carbohydrate transport. Planta 198:171-178.

Goodall G.E., T.W. Embleton, and R.G. Platt. 1981. Avocado fertilization. Univ. Calif. Div. Agr. Sci. (Oakland) Lflt. 2024.

Häfliger B., E. Kindhauser, and F. Keller. 1999. Metabolism of Dglycero-D-heptitol, volemitol, in polyanthus. Discovery of a novel ketose reductase. Plant Physiol. 119:191-197.

LaForge, F.B. 1916. D-mannoketoheptose, a new sugar from the avo- cado. J. Biol. Chem. 28:511-522.

LaForge F.B. and C.S. Hudson. 1917. Sedoheptose, a new sugar from Sedum spectabile. J. Biol. Chem. 30:61-77.

Liu X., P.W. Robinson, M.A. Madore, G.W. Witney, and M.L. Arpaia. 1999a. 'Hass' avocado carbohydrate fluctuations. I. Growth and phenology. J. Amer. Soc. Hort. Sci. 124:671-675.

Liu X., P.W. Robinson, M.A. Madore, G.W. Witney, and M.L. Arpaia. 1999b. 'Hass' avocado carbohydrate fluctuations. II. Fruit growth and ripening. J. Amer. Soc. Hort. Sci. 124:676-681.

Madore, M.A. 1990. Carbohydrate metabolism in photosynthetic and nonphotosynthetic tissues of variegated leaves of Coleus blume $i$ Benth. Plant Physiol. 93:617-622.

Nordal A. and A.A. Benson. 1954. Isolation of mannoheptulose and identification of its phosphate in avocado leaves. J. Amer. Chem. Soc. 76:5054-5055.

Okuda T. and K. Mori. 1974. Distribution of mannoheptulose and sedoheptulose in plants. Phytochemistry 13:961-964.

Rendig V.V. and E.A. McComb. 1964. Some nonfermentable free sugars in the leaf-petiole fraction of alfalfa (Medicago sativa). J. Agr. Food Chem. 12:421-423.

Richtmyer N.K. 1970. The isolation of volemitol and other polyhydric alcohols from avocado seeds. Carbohydrate Res. 12:135-138.

Snyder, R., D.W. Henderson, W.O. Pruitt, and A. Dong. 1985. California irrigation management information system: Final report land, air, and water resources papers 10013 A, B, C. Dept. Land, Air, Water Resources, Univ. Calif., Davis.

Tingwa, P.P. and R.E. Young. 1975a. Studies on the inhibition of ripening in attached avocado (Persea americana Mill.) fruits. J. Amer. Soc. Hort. Sci. 100:447-449.

Tingwa P.P. and R.E. Young. 1975b. The effect of indole-3-acetic acid and other growth regulators on the ripening of avocado fruits. Plant Physiol. 55:937-940.

Whiley, A.W. and B. Schaffer. 1994. Avocado, p. 1-35. In B. Schaffer and P.C. Andersen (eds.). Handbook of environmental physiology of fruit crops. vol. 2. Subtropical and tropical crops. CRC Press, Boca Raton, Fla.

White, A, A.B. Woolf, F.R. Harker, and M.W. Davy. 1999. Measuring avocado firmness: Assessment of various methods. World Avocado Congr. IV Proc., Uruapan, Mexico, Oct. 1999. Revisita Chapingo Serie Horticultura 5:389-392.

Williams, K.T., E.F. Potter, and A. Bevenue. 1952. A study, by paper chromatography, of the occurrence of nonfermentable sugars in plant materials. J. Assn. Offic. Agr. Chem. 35:483-485. 